anæsthetic. Neitber is it followed by pain; indeed, where aching of the testicle has previously been pretty severe, relief is the immediate result.

Rather than give the details of any one case, I prefer to offer here an analysis of my results. I have operated on thirty-two cases. Not one has been followed by shiverings, erysipelas, or other dangerous symptom. Three had some suppuration : the pus found its way out of the first puncture in two of these; in the third, a small abscess formed in the walls of the scrotum, an opening a third of an inch long emptied it, and it rapidly healed. In every ase the testicle has begun to resume its size and hardness soon after operation. Those that returned to observation after a year or more were found to have quite recovered normal condition, except one. Two cases I saw after five and after seven zears. The former had, through bad habits, a double varicocele; the testicles, previous to operation, were very small and soft; he was pretty nearly emasculate; now the organs are firm, healtby, and very good. The other, seen after seven years, had become the father of two children, stated to be strong and bealthy. The one case referred to above, which after two years had not recovered normal condition, was one of left varicocele; the testicle was at the time of operation quite flabby; it was at the end of two years certainly better, but still very soft, and the patient believed it to have regained function; the man was a very feeble person, of phthisical history. Although I have asked all my patients to call upon me in case there were any return of the disease, I have never seen one of them with such complaint. George-street, Hanover-square.

\section{OBSERVATIONS ON MINERS' NYSTAGMUS. A NEW DISEASE.}

BY CHARLES BELL TAYLOR, M.D., F.R.C.S. E., SURGEON TO THE NOTIINGHAM AND MTDLAND EYE INFIRMARY.

DURINa the past twelve years the neighbouring colliery district has furnished me with several examples of a peculiar malady which I have not found described in any of our text-books, and which I presume to be, therefore, a comparatively new or hitherto unstudied affection. I have called it " miners' nystagmus" from the peculiar oscillating motions of the eyeball which are characteristic of the disease, and from the fact that I have only observed it occurring in adults, and independent of other ocular defects, among the men employed in the coalpits of this and the neighbouring counties.

It was formerly supposed that nystagmus was incurable, always developed itself in infancy (although it might not in slight cases attract attention until the patient began to read), and was caused either by imperfect nervous perception or structural changes in the transparent media of the eyeball. In miners' nystagmus, however, the disease is usually curable, is developed in adults and aged persons previously healthy, is not accompanied by disease of the nerve or structural change of the eyeball, and is, as a rule, only to be noticed when the patient attempts fixation, especially in a stooping position. The oscillating motions are cansed by alternating contractions of the recti or oblique muscles, and, in all the cases I have observed, have been either horizontal or rotatory.

The affection appears to be analogous to writers' cramp, pianists' and telegraphists' cramp, or the similar affection of the gastrocnemii occasionally observed in ballet-dancers. It may be developed in any or all of the muscles supplied by the third nerve, and is clearly caused by the overtaxing of these organs. The patient makes a great and sustained effort to see in an imperfect light; the muscles engaged in the accommodative strain are overburdened, in course of time give way, and at last, whenever called upon, just as in the analogous cases cited above, become, as it were, agitated and fluttered, escape from the control of the will, and perform irregular motions. It is clear from these facts that in all cases in which a considerable degree of exertion of the ocular muscles is required for distinct vision nystagmus may, under certain concomitant favouring circumstances, be developed. Hitherto the cause of nystagmus has been referred to, and might usually be readily detected in, the ejeball itself, but these cases demonstrate that causes external to the organ, and independent of any structural or apparent functional changes, may occasion all the phenomena of that disease, or, more properly speaking, symptom of disease. Nystagmus generally persists so long as its cause remains, and, if developed in childhood, may continue even after its removal; but in 'miners' nystagmus" the aphorism sublata causa tollit effectus applies, and, as a rule, change of occupation and working in a good light are all that is necessary to effect a cure. In my first case, sent by my friend Dr. Forbes, of Eastwood, some years ago, I did not recognise the cause of the affection, and tried various remedies-such as the continuous galvanic current, blue spectacles, atropine, tenotomy of the affected muscles, and tonic and alterative remedies - with but little benefit. Since then similar cases have led me to a perception of the true cause of the disease, and the proper method of cure, which, as I have just remarked, consists essentially in a change of occupation, supplemented by such auxiliary treatment as may, in each case, appear to be specially indicated. It is worthy of note that the men are very apt to attribute their imperfect sight to one or other of the accidents which are so deplorably frequent among workmen underground. This is natural, of course, and acquires importance from a medico-legal point of view; but I have hitherto been unable to satisfy myself that in any case the accident had caused the affection, though readily inclined to grant that the nervous commotion and depressing influence of such injuries may aggravate an already existing disease, specially one so apt to be intensified by any nervous excitement.

In the three cases at present under treatment, and reported below, as samples of nine or ten otbers which I have had under my care, this disposition is evident in two, though there is little doubt that sight had been failing some time before the accidents to which the men ascribed their imperfect vision.

Case 1.-James B-, aged fifty-six, of Staveley, came under my care on Feb. 3rd, 1875, complaining of dimness of vision and consequent inability to work. On examination with the ophthalmoscope, and directing the patient to look "inwards," the eyeballs immediately manifested the peculiar oscillating motions characteristic of " miners" nystagmus." The motions were aggravated by stooping or by an imperfect light. He stated that he had worked in a pit since he was seven years of age, and had not noticed anything wrong with his sight until four months ago, when he was crushed with some falling bind. He admitted, however, on further examination, that vision had been dimmish for some time, probably a year before the accident. He had been blistered by his surgeon, and had a seton in his back, "to elear the sight," without benefit. The optic discs were healthy, and there was no disease of the eyeball to account for the involuntary motions. He was ordered small doses of iodide of potassium as a placebo, and directed to abandon his occupation underground. Under this treatment his sight gradually improved, and on the date of his last visit (May 15th) was nearly normal, although by fixing his attention on any small object, especially while stooping, it was still possible to set the eyeballs oscillating to a slight degree.

CASE 2-Philip A-, of Seamer, near Staveley, aged thirty-seven, came under my care in January, 1875, complaining of dimness of vision, which, he says, was caused by a crush which be received in the pit on Nov. 25 th, 1874 . Has worked in a pit since ten years of age, and sight has always been good until lately. Is positive that the accident has caused his imperfect sight. Nothing peculiar is to be observed on glancing furtively at the patient, awaiting his turn for examination, and his eyeballs are at rest; but on questioning and looking at him, the effort to return your gaze is quite sufficient to set the eyeballs rolling rapidly from side to side. No disease or structural change was manifest on ophthalmoscopic examination; the patient had recovered from his accident, and was otherwise in good health. He was ordered to abandon his occupation, get some work on the pit-bank above-ground, and to take acetate of strychnia thrice daily, in increasing doses. Under this treatment he rapidly improved, and on May 20th, the date of his last visit, it was diffcult, either by stooping, fixation, 
or diminished light, to induce sufficient oscillation to demonstrate the case to a medical friend who was present.

CASE 3. - Jacob S-, of Kimberley, aged forty-four, came under my care in November, 1872, complaining of dimness of vision, so great that he had been obliged to give up his work. He said that on fixing his lamp in order to break up coal the light began to dance about; he turned giddy; objects seemed enveloped in a mist; and he was obliged to desist. On examination with the ophthalmoscope in a light room, the peculiar fanning motion was at once developed, and the nature of the complaint made manifest. No disease of the optic discs or eyeballs was to be detected, and his health was otherwise good. He was ordered to give up working in twilight or by artificial light, to wear blue glasses, and to take strychnine three times a day. Under this treatment he gradually improved, and in eight months time he ceased to attend.

It is unnecessary here to reproduce notes of similar cases, for the essential features are the same in all. So far as I ean ascertain, this is a new disease; but, however much we may regret the addition of one more malady to our nosological list, I think we may at the same time congratulate ourselves that it is so amenable to treatment, and that the remedy is so simple, easy of application, and generally successful.

Nottingham.

\section{NOTES ON A}

CASE OF PY EMIA IN PRIVATE PRACTICE.

\section{By LEONARD CANE, M.D. \& B.S. LoND.}

THE following notes of a case of pyæmia present some features of interest, and may be worth recording.

I was called on the 9 th of September, 1874 , to see a gentleman holding the post of Government contractor. He told me that he had recently come by train several hours' journey when he was seized with a sudden attack of "shortness of breath," caused, as he said, by a lump coming down in his neck from under his jaw. The dyspnœa had been relieved by rubbing his neck briskly with some oil. The only history he then gave of his illness was that he had got very wet in a rough sea passage, and believed he had caught cold and that it had settled in his throat.

On examination I found a large swelling, about the size of a hen's egg, below the jaw on the right side, occupying the situation of the submaxillary gland. The swelling was tender, hard, and painful, and appeared to be an inflamed lymphatic gland. The fauces were seen to be red, especially on the right side, and there were some traces of old ulceration. On inquiry, he stated that he had had an ulcerated sore-throat several months previously, and that, though this had got quite well, he did not think he had been right ever since. He had felt "chilly," but had had no distinct rigors. He was perspiring very freely. Pulse 110 ; temperature $99.4^{\circ}$. Ordered saline mixture, and liniment for his throat.

He improved for a few days. The swelling rapidly increased to the size of an orange, and then, without any other symptom, slowly subsided. He was then able to take solid food, which he had avoided before, owing to the pain it caused him.

On September $12 \mathrm{th}$, feeling much better and being anxious to get home, he went in a cab for a distance of about a mile. On arriving at his destination he felt very "chilly," and at once went to bed. On the next day he was attacked with diarrhoea and vomiting, and his evening temperature ran up to $100 \cdot 8^{\circ}$. The diarrhce and sickness soon ceased, and during the next week he seemed to improve slightly. The chief symptoms during that time were debility and a high evening temperature $\left(100^{\circ}\right.$ to $\left.101^{\circ}\right)$.

On September 20th (eleventh day of illness) he suffered from one or two severe rigors, followed by profuse sweating. He now for the first time complained of pain in his left hip. There was nothing that could be detected wrong with the hip beyond a little pain in moving the limb. The diarrhoea became very troublesome; and the stools were remarkably offensive. The urine became highly albuminous (one-third albumen), containing some blood-corpuscles, casts, and epithelium. He now sweated profusely, the perspiration pour. ing off him and wetting the bedclothes. He was extremely restless, and could not sleep at night. I now gave him two and a half grains of quinine every two or three hours, with a little opium to counteract the diarrhœa, and a chloral draught at night.

At about this date (Sept. 20th) I noticed for the first time a small quantity of blood on the nose; and, on inquiry, found that he had suffered from a discharge from the nose, occasionally of a bloody nature, but usually like ordinary mucus, for several weeks. I accordingly made further inquiries into his history, and learnt the following facts. $\mathrm{He}_{\mathrm{e}}$ stated that he was a native of the West Indies, and that he had yellow fever when about twelve years old. A few years ago be had syphilis, having a sore on the penis. This was followed by a few spots on the leg, one of which caused deep ulceration, and of which the cicatrices still remained. About a year before his present illness he was in a railway accident, but, though he was much bruised at the time, he did not receive any wound.

About ten weeks before his illness he married, and states that a few days after his marriage he suffered from "spasmcdic stricture." For this he was obliged to call in a doctor in the middle of the night. The surgeon passed a catheter, and drew off a considerable quantity of bloody urine. He continued to pass small quantities of blood with his urine for several days after this. He now came to live near London, going to the city every day, where he was chiefly employed in tea-tasting, being frequently at the docks. On inquiry, he said that he had seen a great quantity of raw hides, which smelt very badly. He had also been round the surgical wards of a hospital on several occasions. Eight weeks before his illness he had suffered from an ulcerated sore-throat, which he was told was "syphilitic." He said that "one tonsil was nearly eaten away by the disease." Since then he had got much better. He had been over to Ireland, and though he had not felt well there was nothing much the matter with him. He usually noticed that when he blew his nose in the morning be "got rid of a small piece of matter," which he sometimes "spat up." He said that this came from the back of the throat. He continued to do this until I saw him.

On the 21st of September (twelfth day of illness) he suffered from two severe rigors. His morning temperature was $1024^{\circ}$; evening $103.8^{\circ}$. The diarrhœa was profuse, with most offensive stools. He sweated very much after the rigors. The urine was highly smoky in colour, and contained about one half of albumen. On this day he first complained of pain in the right wrist, which he attributed to having "ricked" it by holding a book. The joint was painful and tender, and there was some slight swelling. On the following day the swelling had increased; there was a blush of redness over the back of the wrist, and also some pitting on pressure. The diarrhoa still continued; the sweating was profuse. Temperature $1036^{\circ}$ in the evening. He now became very sallow, but not distinctly jaundiced. He was very restless, tossing about continually. There was not any sweet hay-like odour of the breath. The liver was enlarged, but, not tender.

On Sept. 23rd I met Dr. Wilson Fox in consultation. Dr. Fox found some congestion at the base of the right lung, and also a basic murmur of the heart. Dr. Fox advised a continuance of the quinine with the addition of some digitalis. The next day there was but little change. On Sept. 25th he had another rigor and felt severe pain in the left knee, which began to swell. The swelling advanced rapidly, and in a few hours the knee was double the normal size. This was followed by odema of the whole of the left leg and thigh. The right arm was also much swollen, and there appeared to be some fluctuation in the wrist-joint. On the following day (26th) he appeared to be much lower, the reapiration became very frequent (35), and there was consolidation of the bases of both lungs. He had a frequent dry cough, but did not expectorate.

Tympanites now set in, and was very troublesome. Dr. Hollings, who saw the case with me for the last few days, advised an enema of assafoetida and of starch and opium This produced some relief. During the next two or three days the chief symptoms were connected with the lungs. The respiration rose to 44 ; pulse 130 ; temperature $104^{\circ} \mathrm{F}$ 